\title{
The PSEN1 I143T mutation in a Swedish family with Alzheimer's disease: clinical report and quantification of $A \beta$ in different brain regions
}

\author{
Lina Keller ${ }^{1,6}$, Hedvig Welander ${ }^{2,6}$, Huei-Hsin Chiang' ${ }^{1}$, Lars O Tjernberg ${ }^{2}$, Inger Nennesmo ${ }^{3}$, Åsa K Wallin ${ }^{4}$ \\ and Caroline Graff ${ }^{*}, 1,2,5$
}

Early-onset dominantly inherited forms of Alzheimer's disease (AD) are rare, but studies of such cases have revealed important information about the disease mechanisms. Importantly, mutations in amyloid precursor protein (APP), presenilin 1 (PSEN1) and PSEN2, alter the APP processing and lead to an increased amyloid $\beta$-peptide (A $\beta$ ) $42 / 40$ ratio. This, together with other studies on pathogenic mechanisms, show that AB42 is a major player in the etiology of AD. Here, we present a clinical and neuropathological description of a Swedish family with an I143T mutation in the PSEN1 gene, which gives rise to a severe form of $A D$. We also performed an extensive investigation on the concentration and distribution of $A \beta$ species of different lengths in six brain regions from two mutation carriers. Our study showed that $A \beta 42$ and a longer peptide, $A \beta 43$, were present both in plaque cores and in total amyloid preparations, and were each clearly more frequent than A $\beta 40$ in all examined regions, as shown by both mass spectrometry and immunohistochemistry.

European Journal of Human Genetics (2010) 18, 1202-1208; doi:10.1038/ejhg.2010.107; published online 14 July 2010

Keywords: Alzheimer's disease; PSEN1 mutations; amyloid $\beta$-peptide variants; mass spectrometry; neuropathology

\section{INTRODUCTION}

Alzheimer's disease $(\mathrm{AD})$ is a neurodegenerative disorder and a major cause of dementia, characterized by amyloid $\beta$-peptide $(\mathrm{A} \beta)$ deposits and neurofibrillary tangles in brain. ${ }^{1-3} \mathrm{~A} \beta$ is typically 40 or 42 amino acids long and is produced by the sequential cleavages of the amyloid precursor protein (APP) by $\beta$-secretase and $\gamma$-secretase. ${ }^{4}$ The presenilins ( 1 and 2$)$ are important components of the $\gamma$-secretase complex, and harbor its active site and thereby influence its proteolytic effect. $\mathrm{A} \beta 40$ is produced at higher levels, but as $\mathrm{A} \beta 42$ is more hydrophobic and has a stronger tendency to polymerize into neurotoxic species, it seems to be of particular importance in $\mathrm{AD}$ pathogenesis. ${ }^{5-7}$ This is supported by studies on mutations in $A P P$, presenilin 1 (PSEN1) and PSEN2, which show an increased A $\beta 42 / 40$ ratio. ${ }^{8}$ Five mutations have previously been described in families from Sweden: two mutations in $A P P$ (the APP Swedish ${ }^{9}$ and the APP Arctic mutations ${ }^{10}$ ) and three in PSEN1 (M146V, H163Y, ${ }^{11}$ and $\mathrm{R}_{2} 69 \mathrm{H}^{12}$ ). In the present study, we describe the clinical characteristics of a three-generational Swedish family found to have the I143T PSEN1 mutation, which causes a rapidly progressing type of early-onset $\mathrm{AD}$ (EOAD). The $\gamma$-secretase complex with the I143T mutation in PSEN1 has been suggested to produce $\mathrm{A} \beta$ peptides of different lengths. ${ }^{13}$ We recently reported that a longer variant, $\mathrm{A} \beta 43$, is present in plaque cores and in total amyloid preparations obtained from sporadic and familial $\mathrm{AD}$ brains, and was indeed found more frequently than $\mathrm{A} \beta 40 .{ }^{14} \mathrm{~A}$ quantitative approach was used to study $\mathrm{A} \beta 40, \mathrm{~A} \beta 42$, and $\mathrm{A} \beta 43$ in two mutation carriers diagnosed with a severe and aggressive form of EOAD by examining samples taken from six brain regions, including the frontal, parietal, temporal, and occipital cortex, as well as anterior hippocampus and cerebellum. High-performance liquid chromatography (HPLC) coupled with an electrospray ionization ion-trap mass spectrometer (MS) was used. In parallel, we performed immunohistochemistry on consecutive sections using antibodies directed against $\mathrm{A} \beta 40, \mathrm{~A} \beta 42$, and $\mathrm{A} \beta 43$. In addition, secreted and cellular $\mathrm{A} \beta$ was analyzed in cultured fibroblasts from mutation carriers and controls using a highly sensitive ELISA.

\section{MATERIALS AND METHODS}

The study was approved by the Regional Ethics Committee in Stockholm and informed consent was obtained from the participants, or from a proxy.

Sample preparation for neuropathological examination and immunohistochemistry

The left halves of the brains were frozen after death and the right halves were fixed in $4 \%$ formaldehyde. Samples from the different regions, such as hippocampus, amygdala, basal ganglia, thalamus, mesencephalon, brainstem, and cerebellum, were collected from the fixed brains. In addition, one gross section of the cerebral hemispheres was collected from each patient.

Staining was performed on $5-\mu \mathrm{m}$-thick formaldehyde-fixed paraffinembedded sections. Sections were routinely stained with hematoxylin and eosin, Luxol fast blue, Bielschowsky, and AT8 antibody. Some sections were also Congo stained to detect amyloid. Immunohistochemistry was performed on

${ }^{1}$ Department of Neurobiology, Care Sciences and Society (NVS), Karolinska Institutet, KI-Alzheimer Disease Research Center, Stockholm, Sweden; ${ }^{2}$ Department of Neurobiology, Care Sciences and Society (NVS), KASPAC, Karolinska Institutet, KI-Alzheimer Disease Research Center, Huddinge, Sweden; ${ }^{3}$ Department of Laboratory Medicine, Division of Pathology, Karolinska Institutet, Karolinska University Hospital, Stockholm, Sweden; ${ }^{4}$ Clinical Memory Research Unit, Department of Clinical Sciences, Lund University, Malmö, Sweden; ${ }^{5}$ Genetics Unit, Department of Geriatric Medicine, Karolinska University Hospital Huddinge, Stockholm, Sweden

${ }^{*}$ Correspondence: Dr C Graff, Department of Neurobiology, Care Sciences and Society (NVS), Karolinska Institutet, KI-Alzheimer Disease Research Center, Novum, Huddinge SE-141 86, Sweden. Tel: +46 8585 83619; Fax: +46 8585 83645; E-mail: caroline.graff@ki.se

${ }^{6}$ These authors contributed equally to this work.

Received 20 January 2010; revised 1 June 2010; accepted 9 June 2010; published online 14 July 2010 
sections pre-treated with formic acid (FA; $88 \%$ ) for $10 \mathrm{~min}$. Staining was performed using a C-terminal-specific antibody diluted in Bond primary antibody diluents (Vision BioSystems Limited, Newcastle Upon Tyne, UK), 1:4000 for A $\beta 40$ (BioSource, Camarillo, CA, USA), 1:50 for A $\beta 42$ (BioSource), and 1:8000 for A $\beta 43$ (GeneTex, Irvine, CA, USA). Preparations were visualized in a Bond Polymer Refine Detection system (Vision BioSystems Limited). The specificity of the $\mathrm{A} \beta 43$ antibody was tested as previously described. ${ }^{14}$

\section{Molecular genetics}

DNA was extracted from peripheral blood (cases III:1 and III:2) or from formalin-fixed paraffin-embedded tissue (case II:2). The PSEN1 gene exons $2-11$, the coding part of exon 12 , and at least 40 flanking nucleotides were sequenced in both directions using an ABI 3100 genetic analyzer and ABI PRISM BigDye Terminator v3.1 Cycle Sequencing Kit (Applied Biosystems, Foster City, CA, USA), with primer pairs available on request. The restriction enzyme Tsp45 (New England BioLabs, Ipswich, MA, USA) was used to confirm the presence of the mutation. The APOE genotype for case III:2 was obtained by the SNaPshot multiplex system (Applied Biosystems), whereas the genotypes for III:1 and II:2 were obtained from medical records.

\section{Plaque core preparations}

Plaque cores obtained from frozen frontal, parietal, temporal, and occipital cortex samples, as well as from the anterior hippocampus and cerebellum were prepared using the same procedure as described in Welander et al. ${ }^{14}$ Initially, $0.5-1 \mathrm{~g}$ of the brain tissue was homogenized in Tris-buffered saline (TBS; $\mathrm{pH}$ 7.4) supplemented with Complete protease inhibitor mixture (Roche Applied Science, Basel, Switzerland; $4 \mathrm{ml}$ buffer per $\mathrm{g}$ of the tissue) using a mechanical pestle homogenizer (IKALaborteknik RW20, IKA Labortechnik, Staufen, Germany). The homogenate was centrifuged at $4000 \mathrm{~g}$ for $2 \mathrm{~min}$ at $4{ }^{\circ} \mathrm{C}$ and the resulting pellet was then washed in TBS and stained overnight with Congo red (50\% saturated in TBS). The pellet was filtered through a $100 \mu \mathrm{m}$ nylon mesh (Millipore Corporation, Bedford, MA, USA), adjusted to $46 \%$ sucrose and centrifuged at $16000 \mathrm{~g}$ for $1 \mathrm{~h}$ at $4^{\circ} \mathrm{C}$, then followed by one more centrifugation of the pellet at $16000 \mathrm{~g}$ for $5 \mathrm{~min}$ at $4^{\circ} \mathrm{C}$ and dilution in $1 \%$ SDS in TBS. After filtration through a $60-\mu \mathrm{m}$ nylon mesh (Millipore Corporation) and centrifugation at $16000 \mathrm{~g}$ for $5 \mathrm{~min}$ at room temperature $\left(24^{\circ} \mathrm{C}\right)$, the pellet was washed three times in TBS buffer and centrifuged at $16000 \mathrm{~g}$ for $5 \mathrm{~min}$ at room temperature $\left(24^{\circ} \mathrm{C}\right)$. The final pellet was stored at $-20^{\circ} \mathrm{C}$.

\section{Preparation of SDS-insoluble brain homogenates}

A previously described protocol for SDS preparations was followed. ${ }^{14}$ In brief, the samples were homogenized as described above. The homogenate was centrifuged at $50000 \mathrm{~g}$ for $1 \mathrm{~h}$. The resulting pellet was re-homogenized in TBS with $1 \%$ SDS and centrifuged at $50000 \mathrm{~g}$ for $1 \mathrm{~h}$. This procedure was repeated three times. The final pellet was washed five times in TBS and stored at $-20^{\circ} \mathrm{C}$.

\section{Dissolution and cleavage of brain samples}

The purified plaque cores as well as pellets from the SDS preparations were dissolved in $80 \%$ FA and $4 \mathrm{mg}$ of cyanogen bromide $(\mathrm{CNBr})$ in a shaker at 600 r.p.m. overnight at $37^{\circ} \mathrm{C}$. $\mathrm{CNBr}$ cleaves the methionine at the C-terminal end (generating A $\beta 36$-x fragments). Samples were prepared for LC-MS/MS analysis by concentrating and desalting the samples using C 18 ZipTips (Millipore Corporation) according to the manufacturer's instructions, and then dried in a vacuum centrifuge (Maxi dry lyo, Heto, Alleröd, Denmark) and dissolved in $40 \mu \mathrm{l}$ of $0.1 \%$ FA. Finally, $0.5 \mu \mathrm{l}$ of the plaque core samples and the SDS preparations was injected into the LC-MS/MS analysis system.

\section{Quantification}

The synthetic $\mathrm{A} \beta$ peptides $\mathrm{A} \beta 36-40, \mathrm{~A} \beta 36-42$, and $\mathrm{A} \beta 36-43$ (Bachem, Basel, Switzerland) were used as standards for quantifications as described previously. ${ }^{14}$ The peptides were dissolved in $80 \%$ FA and diluted in $0.1 \%$ FA. Standard curves were plotted by mixing $\mathrm{A} \beta 36-40, \mathrm{~A} \beta 36-42$, and $\mathrm{A} \beta 36-43$ at a ratio of 20:20:1 and by injecting $1 \mu \mathrm{l}$ of $500,200,50$, and $20 \mathrm{fmol}$ of $\mathrm{A} \beta 36-40$ and $A \beta 36-42$, and $25,10,2.5$, and $1 \mathrm{fmol}$ of $A \beta 36-43$ in the same solution. The monoisotopic masses for the $\mathrm{A} \beta$ fragments were plotted as extracted ion chromatograms. The peak areas were used in the equations from the standard curves to calculate the concentrations of $\mathrm{A} \beta$ in the tissue samples, which were expressed as nmol of $\mathrm{A} \beta$ per $\mathrm{g}$ of wet brain tissue. The total $\mathrm{CNBr}$ cleavage yield as well as the yield from the plaque core preparation procedure as established previously were taken into account in the calculations. ${ }^{14}$

\section{HPLC-MS/MS}

The samples were injected into a high-capacity enrichment column chip with a 160 -nl enrichment column and a $75 \mu \mathrm{m} \times 150 \mathrm{~mm}$ analytical column packed with Zorbax C18-SB 5- $\mu \mathrm{m}$ material (Agilent Technologies, Santa Clara, CA, USA). As described before, ${ }^{14}$ peptides were eluted using a water/acetonitrile (ACN) gradient supplemented with $0.2 \% \mathrm{FA}$, from 2 to $14 \% \mathrm{ACN}$ in $20 \mathrm{~min}$ and from 14 to $95 \% \mathrm{ACN}$ in $20 \mathrm{~min}$. The flow rate was $0.4 \mu \mathrm{l} / \mathrm{min}$, delivered by an Agilent 1200 nano pump (Agilent Technologies). The column chip was coupled to an Agilent ion trap mass spectrometer (6330 Ion Trap LC/MS, Agilent Technologies). Mass spectra were recorded from the mass to charge ratio $(m / z 420$ to $m / z 750)$. The identity was confirmed using MS/MS data.

\section{Fibroblast culture}

Skin biopsy samples were taken and fibroblast cells were prepared as described. ${ }^{15}$ Fibroblast cell cultures from case III:1 were compared with selected cases, including an individual with the APP KM670/671NL Swedish mutation (APPSwe; onset age 58, biopsy at 66 years) and three unrelated, gendermatched and cell-passage-matched controls (mean age at biopsy: 43.7 years; range 26-53 years). Measurements of secreted and cellular $A \beta 40$ and $A \beta 42$ using ELISA provided the basis for comparison. The fibroblast cells were cultured in duplicate in $5 \mathrm{ml}$ of minimum essential medium with Earl's salt (MEM), supplemented with 7.5\% heat-inactivated fetal bovine serum, $10 \mathrm{~mm}$ HEPES, $1.2 \%$ L-glutamine, and $1.2 \%$ pencillin-streptomycin (all reagents from GIBCO, Invitrogen, Carlsbad, CA, USA). In parallel, fibroblast samples from the I143T, the APPSwe, and two of the controls were also cultured in the presence of the $\gamma$-secretase inhibitor L-685.485 (Bachem, Bubendorf, Switzerland) at a final concentration of $10 \mu \mathrm{m}$ till the collection of the cell medium. When the cells reached $\sim 100 \%$ confluency, the cell medium was replaced with serum-free MEM, supplemented with $10 \mathrm{mM}$ HEPES and $1.2 \%$ L-glutamine, and incubated for $24 \mathrm{~h}$, after which Complete protease inhibitor cocktail (Roche Applied Science) was added to the cell culture. The medium was removed, aliquoted in Genuine Axygen Quality 1.5-ml microtubes (Axygen, Union City, CA, USA), and stored at $-80^{\circ} \mathrm{C}$ for future analysis. The remaining cells were treated with $1 \mathrm{ml}$ of $1 \times$ RIPA buffer $(150 \mathrm{~mm} \mathrm{NaCl}$, $1 \%$ NP- $40,0.5 \%$ deoxycholic acid, $0.1 \%$ SDS, $50 \mathrm{~mm}$ Tris, $\mathrm{pH} 8$ ) containing Complete protease inhibitor cocktail (Roche Applied Science), and harvested by scraping on ice. The cells were collected in Genuine Axygen Quality $1.5-\mathrm{ml}$ microtubes (Axygen) and centrifuged at $25000 \mathrm{~g}$ for $1 \mathrm{~h}$ at $4{ }^{\circ} \mathrm{C}$. The cell pellet and the supernatant (sup1) were stored at $-80^{\circ} \mathrm{C}$ for future analysis.

\section{ELISA}

$\mathrm{A} \beta 40$ and $\mathrm{A} \beta 42$ secreted into the cell medium, and cellular (RIPA-soluble) $\mathrm{A} \beta 40$ and $\mathrm{A} \beta 42$ were measured in triplicate using ELISA (Human/Rat $\beta$-Amyloid (40) ELISA Kit Wako II and Human/Rat $\beta$-Amyloid (42) ELISA Kit Wako, High-Sensitive from WakoPure Chemical Industries, Osaka, Japan). As the levels of secreted $\mathrm{A} \beta 40$ were below the detection limit for the Wako kit, secreted $\mathrm{A} \beta 1-40$ in the medium was instead analyzed using the Human Amyloid- $\beta$ (1-40) (FL) Assay Kit-IBL (IBL International GmbH, Hamburg, Germany). FLUOStar Galaxy (Thermo Scientific, Fremont, CA, USA) was used to measure the fluorescence. Before the cell medium samples and standards were loaded on the ELISA plate, $5 \times$ RIPA buffer was added to a final concentration of $1 \times$ RIPA buffer. In all, $200 \mu \mathrm{l}$ of $1 \times$ RIPA buffer was added to the cell pellet and sonicated for $10 \mathrm{~min}$, followed by centrifugation at $25000 \mathrm{~g}$ for $1 \mathrm{~h}$ at $4^{\circ} \mathrm{C}$, generating supernatant $2(\sup 2)$. Sup 1 and 2 were pooled; the pooled samples thus contained the $1 \times$ RIPA-soluble cellular $\mathrm{A} \beta$, before loading onto the ELISA plate. The ELISA procedure was according to the manufacturer's protocol, except that TMB was exchanged with a $1 \times$ PBS solution containing $50 \mu \mathrm{M}$ Amplex UltraRed reagent (Invitrogen, Eugene, OR, USA), and $2.2 \mathrm{mM} \mathrm{H}_{2} \mathrm{O}_{2}$ was added to each well before measuring the fluorescence, which was done using a $544 \mathrm{~nm}$ excitation filter and $590 \mathrm{~nm}$ emission filter, 
thus effectively increasing the sensitivity. Concentrations of $\mathrm{A} \beta 40$ and $\mathrm{A} \beta 42$ secreted into the cell medium and RIPA-soluble cellular samples (sup 1 and sup 2) were calculated from standard curves. The mean $\mathrm{A} \beta$ concentration was then normalized against the total cellular protein concentration measured using the Pierce BCA Protein Assay Kit (Thermo Scientific, Rockford, IL, USA) according to the manufacturer's protocol.

\section{RESULTS}

\section{Clinical characteristics}

In a Swedish family, five family members across three generations were affected with pre-senile dementia (Figure 1). The age of onset was $35.6 \pm 2.1$ years (mean $\pm \mathrm{SD}$ ) and age at the first $\mathrm{AD}$-related medical visit was $36.2 \pm 1.9$ years. The mean age of death was $42.4 \pm 1.3$ years and the duration of the disease from onset to death was $6.8 \pm 2.4$ years. Initial symptoms were typical for $\mathrm{AD}$ and included memory impairment, visuospatial difficulties, disorientation, dyspraxia, and dysphasia. However, these symptoms were not always reported until the patient was admitted to hospital in acute condition, owing to falls or epileptic seizures. Additional early findings were coordination difficulties associated with gradually increasing myoclonic jerks, multiple falls, and, in some cases, epileptic seizures. These neurological symptoms made differential diagnosis difficult, specifically between $\mathrm{AD}$ and Huntington's disease. The latter diagnosis was excluded, however, by genetic testing. In the later stages of the disease, psychiatric symptoms such as paranoid delusions, hallucinations, and aggressiveness appeared and, in the first generation, Pick's disease was suspected owing to the observed personality changes. Within the youngest

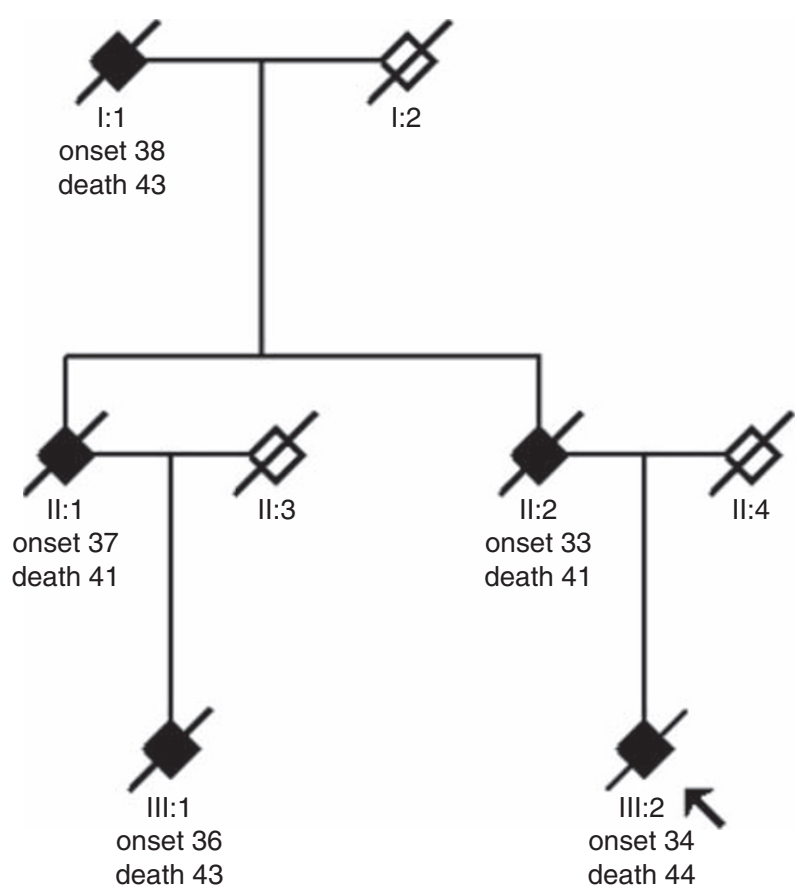

Figure 1 Pedigree of the EOAD family with a PSEN1 I143T mutation. Filled symbols indicate affected individuals and symbols with a diagonal line indicate deceased individuals. Age at onset and age at death are shown below the symbols in years. The proband is indicated with an arrow. Healthy family members have been excluded. Information regarding the diagnoses for case III:2 and case III:1 was obtained by our own clinical examinations and neuropathological examinations. For the first and second generation, information regarding the clinical symptoms, signs, and clinical diagnoses was obtained from the medical records. We also re-examined the autopsy material from case II:2. generation, cholinesterase inhibitor treatment was tried but did not seem to slow down the rapid progression of the disease. Anti-epileptic treatment seemed to reduce myoclonic jerks. For an overview of the clinical presentation, see Supplementary Table 1, and for a detailed description of the symptoms, clinical course, and treatment of the family members, see Supplementary Text 1 .

\section{Neuropathological examination}

Brains from three mutation carriers (cases II:2, III:2, and III:1) were subjected to autopsy. A definite diagnosis of $\mathrm{AD}$ was established for cases III:1 and III:2 according to the CERAD criteria, and Braak stage VI. Case II:2 was diagnosed as atypical AD in 1985, owing to the prominence of pathology associated with the corpus striatum, which are not typically seen in $\mathrm{AD}$ cases. However, a recent re-examination revealed severe $\mathrm{AD}$ pathology. In summary, all brains were severely affected by Alzheimer's pathology and atrophy. Macroscopically, the frontal lobes were especially affected by the thinning of gyri and the reduced cortical thickness, whereas microscopically a large number of plaques were observed, often without a distinct plaque core. Tau pathology, including numerous ghost tangles, was widespread and severe in the hippocampal areas, entorhinal cortex, and amygdala. Superficial spongiform changes and gliosis were present. Interestingly, some neurons in the granular cell layer of the dentate gyrus were immunoreactive for the AT8 antibody, which recognizes the phosphorylated tau. The cerebellum, which often is relatively spared in $\mathrm{AD}$, was clearly affected by amyloid in cases III:1 and III:2. For a detailed neuropathological description, see Supplementary Text 2.

\section{Molecular genetics - identification of the pathogenic mutation}

The family showed a clear pattern of dominantly inherited neurodegenerative disease; the neuropathological investigation of case III:2 prompted us to suspect early-onset $\mathrm{AD}$ and to screen for a mutation in PSEN1. A heterozygous point mutation was found in the second base in codon 143 of exon 5 in PSEN1, which results in an amino-acid exchange of isoleucine to threonine in the second transmembrane region of the PSEN1 protein. Restriction enzyme cleavage of the exon 5 PCR fragment using Tsp45 I resulted in two extra and shorter bands in addition to the 300-bp-long wild-type fragment, thereby confirming the presence of the I143T mutation (data not shown). The mutation was detected in genomic DNA from each of the three cases: II:2, III:1, and III:2 (Figure 1). Moreover, one variation was found in intron 8 (rs165932), which has previously been studied (http://www.alzgene.org/meta.asp?geneID=84). This variation is a common polymorphism and should not be considered as informative. No other genetic variation was found. Cases II:2, III:1, and III:2 were all $A P O E$ \&3 83 homozygotes.

\section{Analysis of $\mathrm{A} \beta \mathrm{C}$-terminal fragments in plaque cores and SDS-insoluble material}

By using LC-MS, we quantified the amounts of the different $\mathrm{A} \beta$ C-terminal variants in plaque cores and the total amyloid SDSinsoluble material from frontal, parietal, temporal, and occipital cortex samples, as well as from the anterior hippocampus and cerebellum of two PSEN1 I143T mutation carriers (cases III:1 and III:2; Figure 1). Standard curves were plotted and used for calculations of the $\mathrm{A} \beta$ concentrations (Supplementary Figures S1A, S1B, and S1C, Supplementary Data). In plaque cores, $\mathrm{A} \beta \mathrm{X}-42$ was readily detected in all regions from both patients. The lowest concentration was found in the cerebellum and the highest in the occipital cortex. $\mathrm{A} \beta \mathrm{x}-43$ was found in all regions from both cases, except for the cerebellum, where it was not detected. In both cases, the highest concentration was found 


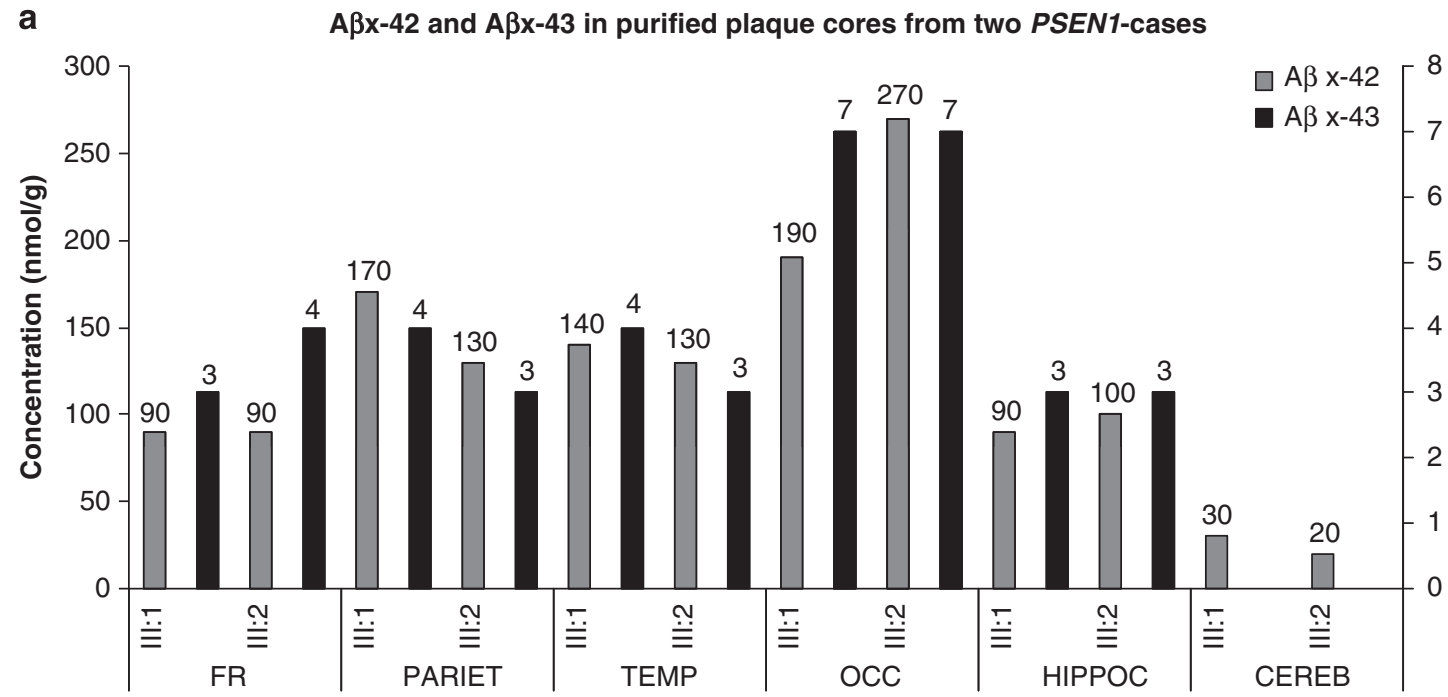

A $\beta$ C-terminal variants in SDS preparations

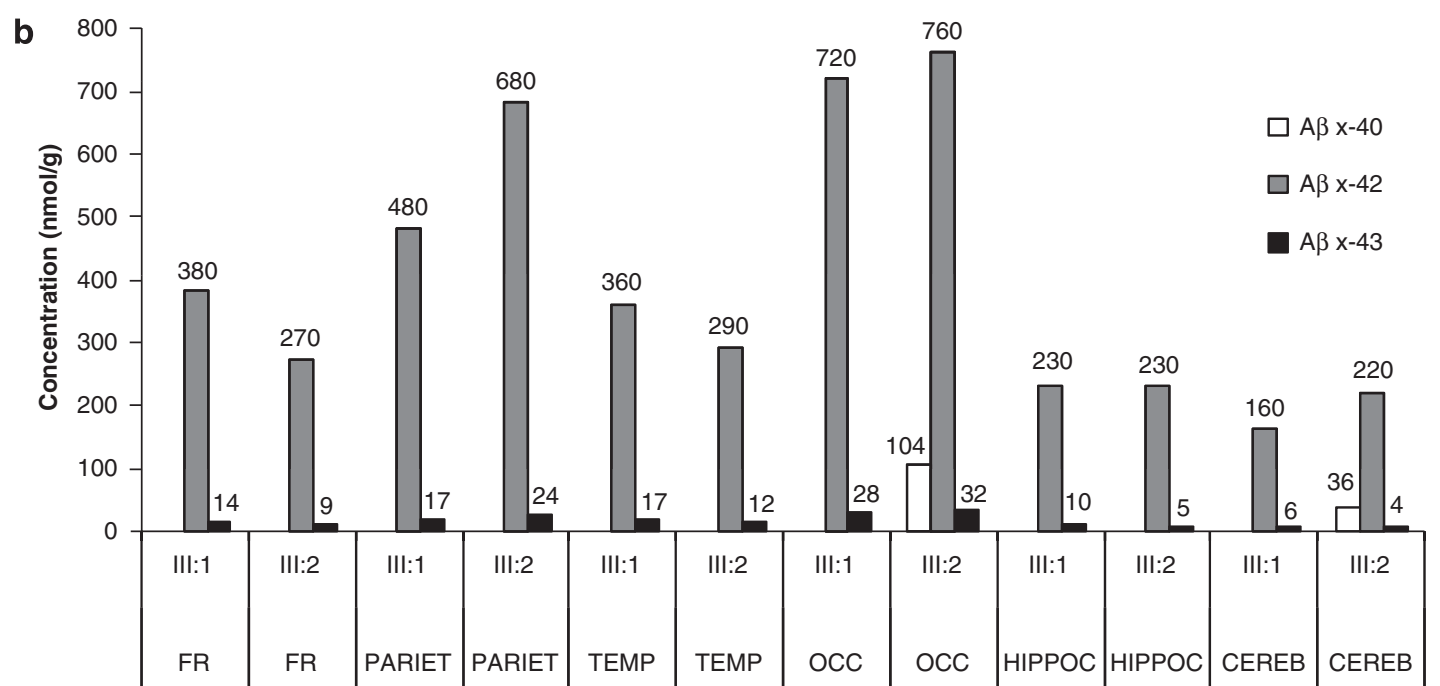

Figure 2 Quantification of $A \beta$ species in plaque cores and SDS-insoluble preparations from frontal, parietal, temporal, and occipital cortex, the anterior hippocampus and cerebellum of two carriers of PSEN1 mutation. (a) Plaque cores from six brain regions of two PSEN1 I143T mutation carriers were cleaved with $\mathrm{CNBr}$ to generate $\mathrm{C}$-terminal $\mathrm{A} \beta$ fragments, and the samples were analyzed by HPLC-MS/MS. Standard curves were used for quantification. The left $y$ axis represents $A \beta 42$ and the right $y$ axis represents A 343 . (b) SDS-insoluble material from six brain regions of two PSEN1 cases was cleaved with CNBr to produce $\mathrm{C}$-terminal $\mathrm{A} \beta$ fragments. The samples were analyzed by HPLC-MS/MS and standard curves were used for quantification. Abbreviations: FR, frontal cortex; PARIET, parietal cortex; TEMP, temporal cortex; OCC, occipital cortex; HIPPOC, hippocampus; CEREB, cerebellum.

in the occipital cortex. Interestingly, $\mathrm{A} \beta \mathrm{x}-40$ was not detected in any of the regions obtained from the two cases (Figure 2a).

We also analyzed total $\mathrm{A} \beta$ in SDS-insoluble material from brain homogenates. $\mathrm{A} \beta \mathrm{x}-42$ was readily detected in all regions in both patients. The lowest concentration of $\mathrm{A} \beta \mathrm{x}-42$ was found in the cerebellum, whereas the highest concentration was found in the occipital cortex. $\mathrm{A} \beta \mathrm{x}-43$ was readily detected in all regions from both cases (Figure $2 \mathrm{~b}$ ). Interestingly, $\mathrm{A} \beta \mathrm{x}-40$ was detected only in the occipital cortex and the cerebellum of case III:2.

\section{Immunohistochemistry}

Antibodies specific for the C-terminus of $\mathrm{A} \beta \mathrm{x}-40, \mathrm{~A} \beta \mathrm{x}-42$, or $\mathrm{A} \beta \mathrm{x}-43$ were used to stain consecutive sections taken from the six regions of the two cases. The staining of $\mathrm{A} \beta \mathrm{x}-40$ was low in the occipital cortex in both cases, and was only detected in vessels (Figure $3 \mathrm{a}$ and $\mathrm{d}$ ), whereas $\mathrm{A} \beta \mathrm{X}-42$ staining was intense in both cases, with numerous immunor- eactive plaques (Figure $3 \mathrm{~b}$ and e). Many immunoreactive plaques were also evident by the $\mathrm{A} \beta \mathrm{x}-43$ antibody (Figure $3 \mathrm{c}$ and $\mathrm{f}$ ). Although the methodology used does not allow for quantification and co-localization of the immunoreactivity, visual inspection in the microscope revealed that $\mathrm{A} \beta \mathrm{x}-42$ and $\mathrm{A} \beta \mathrm{x}-43$ immunoreactivity was detected in both plaques and vessels, whereas $\mathrm{A} \beta \mathrm{x}-40$ showed immunoreactivity mainly in vessels (Figure $3 \mathrm{~g}, \mathrm{~h}$ and $\mathrm{i}$ ). In the cerebellum, $\mathrm{A} \beta \mathrm{x}-40$ staining was clearly visible only in a few vessels, most prominently in case III:2 (Figure $3 \mathrm{j}$ and $\mathrm{m}$ ). $\mathrm{A} \beta \mathrm{x}-42$ staining was observed in vessels in both cases (Figure $3 \mathrm{k}$ and $\mathrm{n}$ ). $\mathrm{A} \beta \mathrm{x}-43$ staining was positive in vessels and the pattern was similar to the $\mathrm{A} \beta \mathrm{x}-42$ staining in both cases (Figure 31 and o). Moreover, extracellular $\mathrm{A} \beta \mathrm{x}-42$ and $\mathrm{A} \beta \mathrm{x}-43$ staining was also observed in an uneven and diffuse pattern in the molecular layer.

The immune staining of the frontal, temporal, and parietal cortex, as well as hippocampus, showed little or no $\mathrm{A} \beta \mathrm{x}-40$ immunoreactivity, 
Occipital cortex from case III:2, Scale bar $=100 \mu \mathrm{m}$
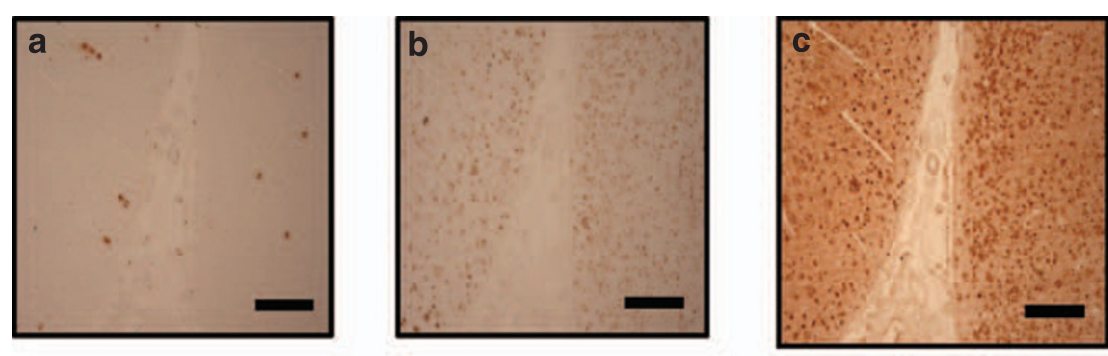

Occipital cortex from case III:1, Scale bar $=100 \mu \mathrm{m}$
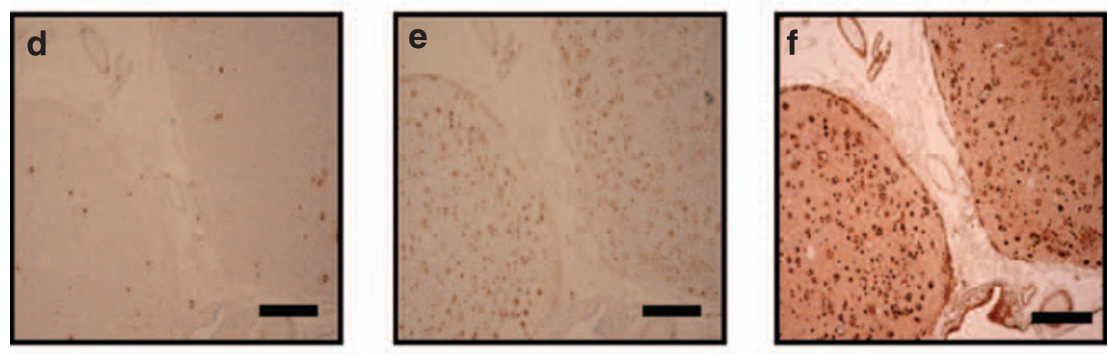

Occipital cortex from case III:1, Scale bar $=20 \mu \mathrm{m}$
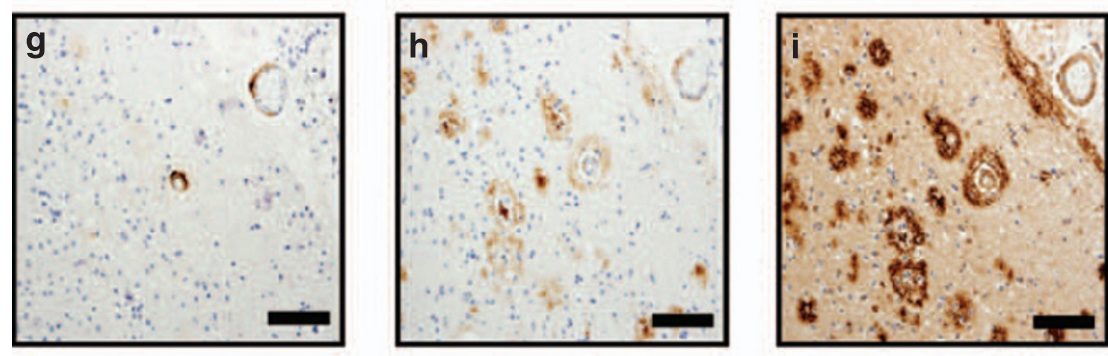

Cerebellum from case III:2, Scale bar $=100 \mu \mathrm{M}$


Cerebellum from case III:1, Scale bar $=100 \mu \mathrm{M}$
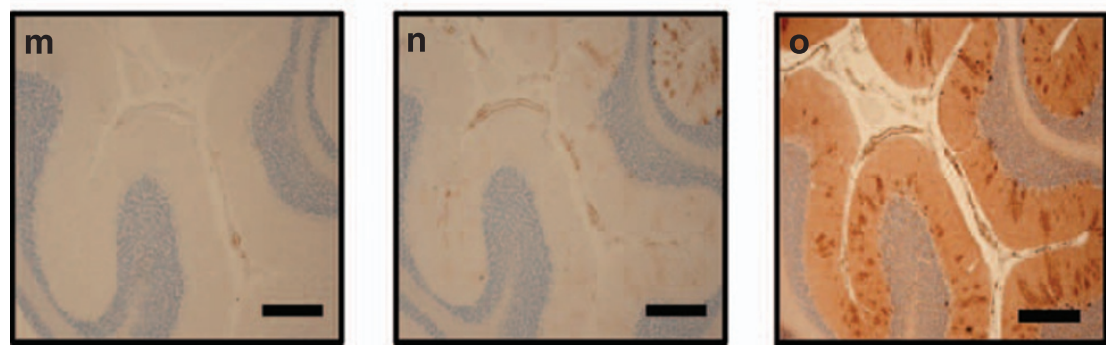

Figure 3 Immunohistochemistry. Immunostaining of amyloid in plaques and vessels in the occipital cortex (a-i) and cerebellum (j-0) from case III:2 and case III: 1 . In each case, three consecutive sections were stained with $C$-terminal antibodies (from left to right) $A \beta x-40, A \beta x-42$, and $A \beta x-43$. Scale bar for figures a-f and $\mathbf{j}-\mathbf{0}$ corresponds to $100 \mu \mathrm{m}$. Scale bar for figures $\mathbf{g}-\mathbf{i}$ corresponds to $20 \mu \mathrm{m}$. 
and when present, it was only observed in vessels, a pattern seen also in the occipital cortex and the cerebellum. $\mathrm{A} \beta \mathrm{x}-42$ was positive in both plaques and vessels, and $\mathrm{A} \beta \mathrm{x}-43$ seemed to have a similar staining pattern (data not shown) in these four regions.

\section{$A \beta$ production in cultured fibroblasts from mutation carriers and controls}

As a complement, a sensitive ELISA was implemented to measure $\mathrm{A} \beta$ production in cultured fibroblasts. Results showed that secreted A $\beta 40$ levels were low in both the PSEN1 I143T mutation carrier (case III:1) and the healthy controls ( $<5 \mathrm{pmol}$ per $\mathrm{g}$ total protein), although the level was five times higher in the APPSwe carrier $(\sim 25 \mathrm{pmol}$ per $\mathrm{g}$ total protein). Secreted $\mathrm{A} \beta 42$ levels were also low ( $\leq 1$ pmol per g total protein) and equal in all samples, except the APPSwe mutation carrier, in which the concentration was about three times higher $(2.8 \mathrm{pmol}$ per $\mathrm{g}$ total protein). In the presence of the $\gamma$-secretase inhibitor, L-685.485, no A $\beta$ was detected (data not shown). The ratio of secreted A $\beta 42 / 40$ was highest in the PSEN1 I143T carrier (0.5; Figure 4a).

The cellular $\mathrm{A} \beta 40$ concentration was equivalent in all samples (40-55 pmol per $\mathrm{g}$ total protein) and significantly higher when compared with secreted $\mathrm{A} \beta 40$ (about two times higher in the APPSwe carrier, and up to 50 times higher in the PSEN1 I143T mutation carrier and the healthy controls). The cellular $\mathrm{A} \beta 42$ concentration was higher across all samples $(\sim 8 \mathrm{pmol}$ per $\mathrm{g}$ total protein) than the secreted A $\beta 42$ concentration (0.5-2.8 pmol per $g$ total protein). Therefore, the cellular ratio of $\mathrm{A} \beta 42 / 40$ was similar $(0.14-0.16)$ across all samples

a

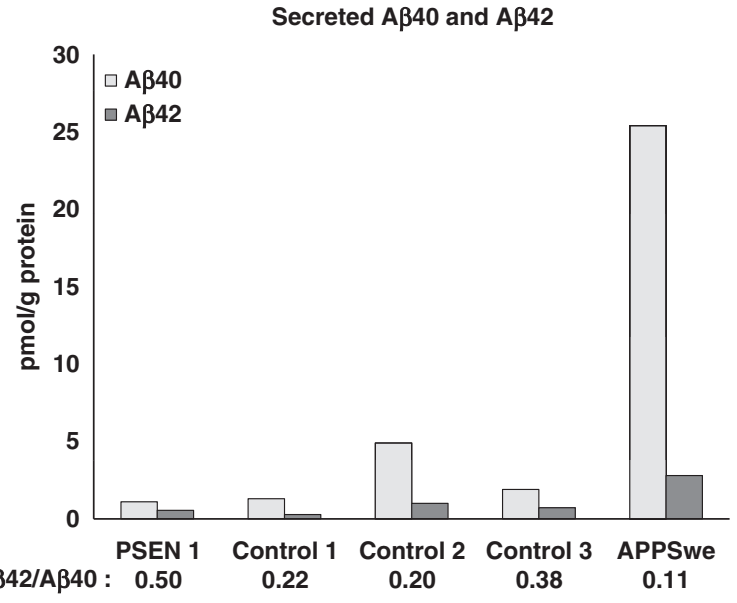

b

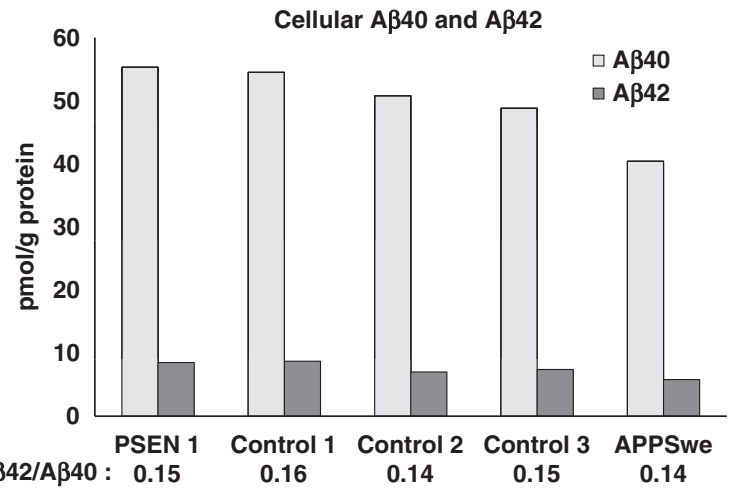

Figure 4 Secreted and cellular $A \beta 40$ and $A \beta 42$ concentrations in cultured fibroblasts. (a) Secreted and (b) cellular $A \beta 40$ and $A \beta 42$ levels from cultured fibroblasts measured by ELISA in a PSEN1 I143T mutation carrier, three healthy controls, and an APPSwe mutation carrier.
(Figure $4 \mathrm{~b}$ ). No significant inhibition of $\mathrm{A} \beta$ was detected in the presence of the $\gamma$-secretase inhibitor, L-685.485 (data not shown).

\section{DISCUSSION}

In the present study, we identified a PSEN1 I143T mutation in three cases diagnosed with neurodegenerative disease from two generations in a Swedish family. This mutation has previously been reported to cause EOAD both in single unrelated cases, related cases and in two families in which segregation was proven, but clinical, neuropathological, and biochemical details have been lacking. ${ }^{16-23}$ The form of EOAD recurring in this family is severe and its mean onset age is reported to be 34 years, whereas the mean age of death is 41.2 years (http://www.molgen.ua.ac.be/ADMutations). Our clinical investigation revealed an aggressive form of $\mathrm{AD}$ with rapid progression and extensive myoclonia. Among the clinical characteristics shown in this Swedish family were insidious impairment of memory, visuospatial disorientation, dyspraxia, and dysphasia, as well as coordination problems, including myoclonic jerks and multiple falls, and in some cases epileptic seizures. The clinical characteristics of the Belgian family with the same mutation, described as early as in 1940 as 'une observation hérédo-familiale de démence avec épilepsie et clonismes, ${ }^{16,18,24}$ were similar to the characteristics of the Swedish family in terms of age at onset, increased aggressiveness, rapid loss of memory, myoclonus, and seizures.

We performed quantitative and qualitative biochemical studies of A $\beta$ pathology on six brain regions sampled from two cousins known to have the I143T mutation. Interestingly, we found that a long $\mathrm{A} \beta$ species, ending with Thr43, was present in plaque cores in all regions except in cerebellum. In all the analyzed regions, $A \beta x-43$ was found more frequently than $\mathrm{A} \beta \mathrm{x}-40$, as shown by both mass spectrometry analysis and immunohistochemistry. The highest concentrations of both $\mathrm{A} \beta \mathrm{x}-42$ and $\mathrm{A} \beta \mathrm{x}-43$ were found in the occipital cortex from both mutation carriers. This supports the notion that the occipital cortex is a plaque core-rich region. ${ }^{25}$ Even though immunostaining in both cases showed that the cerebellum was affected by $\mathrm{A} \beta$ pathology, the lowest plaque core concentration of $\mathrm{A} \beta \mathrm{x}-42$ was found in preparations from this area, and moreover, $\mathrm{A} \beta \mathrm{x}-43$ was not detected by mass spectrometry. The concentrations of $\mathrm{A} \beta \mathrm{x}-42$ were similar in the frontal cortex and anterior hippocampus. The levels were higher in both the parietal and temporal cortex than in either the frontal cortex or anterior hippocampus. There were no significant differences in the concentration of $\mathrm{A} \beta \mathrm{x}-43$ between these regions. In accordance with earlier studies, ${ }^{6}$ we conclude that $\mathrm{A} \beta 42$ is the predominant species in amyloid plaque cores in the $\mathrm{AD}$ brain. Notably, there were no detectable levels of $\mathrm{A} \beta \mathrm{x}-40$ in plaque cores, which is in line with previous results. ${ }^{6}$

As $\mathrm{A} \beta$ is deposited not only in plaque cores in the $\mathrm{AD}$ brain, but also in the walls of the cerebral vessels as diffuse deposits, we studied the total $\mathrm{A} \beta$ from the two cases by analyzing $\mathrm{A} \beta$ peptides in the material from SDS-insoluble preparations. $\mathrm{A} \beta \mathrm{x}-42$ and $\mathrm{A} \beta \mathrm{x}-43$ were readily detected in all regions. The concentrations were highest in the occipital cortex and lowest in the cerebellum. Interestingly, there were no detectable levels of $\mathrm{A} \beta \mathrm{x}-40$ in the SDS-insoluble preparations except in the cerebellum and the occipital cortex of case III:2. The levels of $\mathrm{A} \beta \mathrm{x}-40$ in these regions most likely stem from amyloid in cerebral vessels associated with cerebral amyloid angiopathy, which is reported to be composed mainly of $\mathrm{A} \beta \mathrm{x}-40 .{ }^{6,26} \mathrm{As} \mathrm{A} \beta \mathrm{x}-40$ has a lower aggregation propensity compared with the longer $\mathrm{A} \beta$ species, differences in $\mathrm{A} \beta \mathrm{x}-40$ levels between the cases might be explained by the longer duration of the disease in case III:2, as compared with case III:1. Mass spectrometry data are also supported by the 
immunohistochemical analysis of the six regions, which showed that $\mathrm{A} \beta \mathrm{x}-40$ was localized mainly to the cerebral vessels, whereas $\mathrm{A} \beta \mathrm{x}-42$ and $\mathrm{A} \beta \mathrm{x}-43$ were more prominent in plaques.

Using ELISA, we measured the concentrations of cellular and secreted $\mathrm{A} \beta 40$ and $\mathrm{A} \beta 42$ in cultured fibroblasts sampled from a PSEN1 I143T mutation carrier, an APPSwe mutation carrier, and three healthy controls. The APPSwe mutation carrier differed notably, with higher concentrations of secreted $\mathrm{A} \beta 40$ and $\mathrm{A} \beta 42$ compared with all other samples. Cellular $\mathrm{A} \beta 40$ and $\mathrm{A} \beta 42$ concentrations did not differ significantly between the samples and the levels of $A \beta 42$ were lower in comparison with $\mathrm{A} \beta 40$. The highest ratio of $\mathrm{A} \beta 42 / 40$ was observed in the secreted fraction from the I143T mutation carrier, in line with previous studies on PSEN1 mutations. ${ }^{8,27}$ Although the secreted $\mathrm{A} \beta$ was effectively inhibited in the presence of a $\gamma$-secretase inhibitor, the inhibition was not effective with respect to the cellular levels of $\mathrm{A} \beta$. We do not know why the cellular levels of $\mathrm{A} \beta$ were not reduced by the $\gamma$-secretase inhibitor treatment, but one explanation might be the inability of the inhibitor to enter the human fibroblast cells.

The neurological manifestations in this family are also prevalent in other $\mathrm{EOAD}^{28}$ cases and is considered as secondary to the neurodegenerative process. In the described family, all patients had some neurological dysfunctions, such as falls, myoclonus, or epileptic seizures. Experimental data indicate that high levels of A $\beta$ in hAPP transgenic mouse brains might cause epileptic activity and contribute to cognitive decline. ${ }^{28,29}$ We showed that the PSEN1 mutation carriers had severe $\mathrm{A} \beta$ pathology, using both immunohistochemical staining and mass spectrometry analysis, which might have triggered the myoclonus and epileptic manifestations.

As the $\mathrm{A} \beta 43$ peptide is more hydrophobic than $\mathrm{A} \beta 42$, and as longer forms polymerize faster and at lower concentrations than the more abundant shorter variants, it is plausible that the $\mathrm{A} \beta 43$ isoform also forms toxic oligomers to a greater extent than $\mathrm{A} \beta 40$ and $\mathrm{A} \beta 42$ in vivo. However, in postmortem studies, such as this one, initiating events of the disease cannot be observed. As $\mathrm{A} \beta$ oligomers seem to be of particular importance as neurotoxins, further studies on the presence of A $\beta 43$ oligomers are warranted. Furthermore, in vivo and in vitro studies focusing on $\mathrm{A} \beta 43$ are encouraged, in particular with respect to the design of $\mathrm{A} \beta$ vaccination trials.

In summary, we identified an I143T PSEN1 mutation in a Swedish family, which is the sixth AD mutation found in Sweden that causes an aggressive form of EOAD. We also found a longer $\mathrm{A} \beta$ species, $\mathrm{A} \beta 43$, which was present in each examined brain area, except for the cerebellum, which was, on the other hand, more extensively affected by $\mathrm{A} \beta 40$. Although the absolute levels of $\mathrm{A} \beta 43$ were low, it was clearly more frequent than $\mathrm{A} \beta 40$, thus indicating that $\mathrm{A} \beta 43$ has an important role in the disease process of $\mathrm{AD}$.

\section{CONFLICT OF INTEREST}

The authors declare no conflict of interest.

\section{ACKNOWLEDGEMENTS}

We express our sincere gratitude to the members of the family in our study. We are also thankful to Masakazu Hashimoto for sharing his knowledge about ELISA techniques. This study was financially supported by the Alzheimer Foundation, Foundation for Old Servants, Gun and Bertil Stohne's Foundation, Swedish Brain Power, Marianne and Marcus Wallenberg Foundation, Knut and Alice Wallenberg Foundation, and Dainippon Sumitomo Pharma (Japan).
1 Alzheimer A: Über eine eigenartige Erkrankung der Hirnrinde. Allgemeine Z Psychiatr Psychisch-Gerictliche Med 1907; 64: 146-148.

2 Glenner GG, Wong CW: Alzheimer's disease: initial report of the purification and characterization of a novel cerebrovascular amyloid protein. Biochem Biophys Res Commun 1984; 120: 885-890.

3 Masters CL, Simms G, Weinman NA, Multhaup G, McDonald BL, Beyreuther K: Amyloid plaque core protein in Alzheimer disease and Down syndrome. Proc Natl Acad Sci USA 1985; 82: 4245-4249.

4 Selkoe DJ: Alzheimer's disease: genes, proteins, and therapy. Physiol Rev 2001; 81: 741-766.

5 Hardy J, Selkoe DJ: The amyloid hypothesis of Alzheimer's disease: progress and problems on the road to therapeutics. Science 2002; 297: 353-356.

6 Iwatsubo T, Odaka A, Suzuki N, Mizusawa H, Nukina N, Ihara Y: Visualization of $A \beta 42(43)$ and $A \beta 40$ in senile plaques with end-specific $A \beta$ monoclonals: evidence that an initially deposited species is A $\beta 42(43)$. Neuron 1994; 13: 45-53.

7 Jarrett JT, Berger EP, Lansbury Jr PT: The carboxy terminus of the $\beta$ amyloid protein is critical for the seeding of amyloid formation: implications for the pathogenesis of Alzheimer's disease. Biochemistry 1993; 32: 4693-4697.

8 Borchelt DR, Thinakaran G, Eckman CB et al: Familial Alzheimer's disease-linked presenilin 1 variants elevate A $\beta 1-42 / 1-40$ ratio in vitro and in vivo. Neuron 1996; 7: 1005-1013.

9 Mullan M, Crawford F, Axelman $\mathrm{K}$ et al: A pathogenic mutation for probable Alzheimer's disease in the APP gene at the N-terminus of beta-amyloid. Nat Genet 1992; 1: 345-347.

10 Nilsberth C, Westlind-Danielsson A, Eckman CB et al: The 'Arctic' APP mutation (E693G) causes Alzheimer's disease by enhanced $A \beta$ protofibril formation. Nat Neurosci 2001; 4: 887-893.

11 Clark RF, Hutton M, Fuldner RA et al: The structure of the presenilin 1 (S182) gene and identification of six novel mutations in early onset $A D$ families. Alzheimer's Disease Collaborative Group. Nat Genet 1995; 11: 219-222.

12 Forsell L, Mattila KM, Axelman K, Lannfelt L: The Arg269His and Glu318Gly mutations in the presenilin-1 gene found in Swedish early onset Alzheimer's disease families. Abstract, Sixth International Conference on Alzheimer's Disease and Related Disorders, Amsterdam 1998, pp 18-23.

13 Kumar-Singh S, Theuns J, Van Broeck B et al: Mean age-of-onset of familial Alzheimer disease caused by presenilin mutations correlates with both increased $A \beta 42$ and decreased A $\beta 40$. Hum Mutat 2006; 27: 686-695.

14 Welander H, Frånberg J, Graff C, Sundström E, Winblad B, Tjernberg LO: A $\beta 43$ is more frequent than $A \beta 40$ in amyloid plaque cores from Alzheimer disease brains. J Neurochem 2009; 110: 697-706.

15 Nagasaka $\mathrm{Y}$, Dillner $\mathrm{K}$, Ebise $\mathrm{H}$ et al: A unique gene expression signature discriminates familial Alzheimer's disease mutation carriers from their wild type siblings. Proc Natl Acad Sci USA 2005; 102: 14854-14859.

16 Martin JJ, Gheuens J, Bruyland M et al: Early-onset Alzheimer's disease in 2 large Belgian families. Neurologia 1991; 41: 62-68.

17 Arango D, Cruts M, Torres 0 et al: Systematic genetic study of Alzheimer disease in Latin America: mutation frequencies of the amyloid beta precursor protein and presenilin genes in Colombia. Am J Med Genet 2001; 103: 138-143.

18 Cruts M, Backhovens H, Wang SY et al: Molecular genetic analysis of familial early-onset Alzheimer's disease linked to chromosome 14q24.3. Hum Mol Genet 1995; 4: 2363-2371.

19 Cruts M, Van Broeckhoven C: Molecular genetics of Alzheimer's disease. Ann Med 1998; 30: 560-565.

20 Miravalle L, Takao M, Glazier B, Piccardo P, Vidal R, Ghetti B: Genetic mutations associated with presenile dementia. Neurobiol Aging 2002; 23: Supplementary text page 322.

21 Raux G, Guyant-Marechal L, Martin C et al: Molecular diagnosis of autosomal dominant early onset Alzheimer's disease: an update. J Med Genet 2005; 42: 793-795.

22 Rogaeva EA, Fafel KC, Song YQ et al: Screening for PS1 mutations in a referral-based series of AD cases: 21 novel mutations. Neurology 2001; 57: 621-625.

23 Arai N, Kishino A, Takahashi $\mathrm{Y}$ et al: Familial cases presenting very early onset autosomal dominant Alzheimer's disease with I143T in presenilin-1 gene: implication for genotype-phenotype correlation. Neurogenetics 2008; 9: 65-67.

24 van Bogaert L, Maere M, de Smedt E: Sur les formes familiales précoces de la maladie d'Alzheimer. Mschr Psychiat Neurol 1940; 102: 249-301.

25 Arnold SE, Hyman BT, Flory J, Damasio AR, Van Hoesen GW: The topographical and neuroanatomical distribution of neurofibrillary tangles and neuritic plaques in the cerebral cortex of patients with Alzheimer's disease. Cereb Cortex 1991; 1: 103-116.

26 Gravina SA, Ho L, Eckman CB et al: Amyloid $\beta$ protein $(A \beta)$ in Alzheimer's disease brain. Biochemical and immunocytochemical analysis with antibodies specific for forms ending at $A \beta 40$ or $A \beta 42(43)$. J Biol Chem 1995; 270: 7013-7016.

27 Citron M, Westaway D, Xia W et al: Mutant presenilins of Alzheimer's disease increase production of 42-residue amyloid $\beta$-protein in both transfected cells and transgenic mice. Nat Med 1997; 3: 67-72.

28 Palop JJ, Mucke L: Epilepsy and cognitive impairments in Alzheimer disease. Arch Neurol 2009; 66: 435-440.

29 Palop JJ, Chin J, Roberson ED et al: Aberrant excitatory neuronal activity and compensatory remodeling of inhibitory hippocampal circuits in mouse models of Alzheimer's disease. Neuron 2007; 55: 697-711. 